\title{
Leisure-time and occupational physical activity in relation to cardiovascular risk factors and eating habits in French adults
}

\author{
J-M Oppert ${ }^{1, *}$, F Thomas ${ }^{2}$, M-A Charles ${ }^{3}$, A Benetos ${ }^{2}$, A Basdevant ${ }^{1}$ and C Simon ${ }^{4}$ \\ 'Department of Nutrition, Hôtel-Dieu Hospital (AP-HP), University Pierre-et-Marie Curie (UPMC - Paris 6), 1 place du \\ Parvis Notre-Dame, F-75181 Paris Cedex 04, France: ${ }^{2}$ Centre d'investigations préventives et cliniques (IPC), Paris, \\ France: ${ }^{3}$ INSERM U 780, Villejuif, France: ${ }^{4}$ Department of Nutrition, Hautepierre Hospital, University Louis Pasteur, \\ Strasbourg, France
}

\section{Submitted 11 April 2005: Accepted 13 October 2005}

\begin{abstract}
Objective: To investigate the relationships of two main physical activity domains (during leisure and at work) with cardiovascular risk factors and eating habits.

Design: Cross-sectional study.

Setting: Preventive medicine centre.

Subjects: In 5478 adults (32\% women, aged 20-80 years) who consecutively underwent a standardised health examination, leisure-time physical activity (LTPA; i.e. non-sport leisure and sport activities), occupational physical activity (OPA) and eating habits were assessed by self-administered questionnaires. We analysed sexspecific relationships of LTPA and OPA (in quartiles) with (1) various cardiovascular risk factors and (2) eating habits using analysis of variance and logistic regression, respectively.

Results: In both genders, with and without adjustment for education in addition to age, LTPA was associated negatively with body mass index, body fat, waist circumference, resting heart rate, diastolic blood pressure and triglycerides, and positively associated with high-density lipoprotein cholesterol (all $P \leq 0.005$ ). OPA adjusted for age only was positively associated with most cardiovascular risk factors but these associations were not significant after further adjustment on education (except for waist circumference in women). Age- and education-adjusted LTPA was associated with increased frequency of consumption of fruits (odds ratio $(\mathrm{OR})=2.05$, $95 \%$ confidence interval $(\mathrm{CI}) 1.68-2.52$ in men; OR $=1.90,95 \%$ CI $1.41-2.05$ in women $)$ and vegetables $(\mathrm{OR}=1.81,95 \% \mathrm{CI} 1.48-2.21$ in men; $\mathrm{OR}=2.22,95 \% \mathrm{CI}$ $1.66-2.97$ in women).

Conclusions: The data emphasise the favourable associations of LTPA, a modifiable behaviour, with various cardiovascular risk factors and healthy eating habits. The results also suggest that the relationships of OPA with cardiovascular risk factors depend, at least in part, on socio-economic status as reflected by educational level.
\end{abstract}

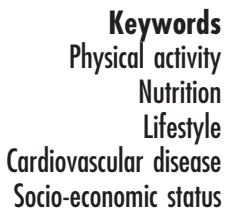

Cardiovascular disease (CVD) remains the leading cause of death in many industrialised countries. It is now well recognised that a physically active lifestyle is associated with decreased CVD risk ${ }^{1}$. One of the mechanisms for decreased CVD risk with increasing physical activity is through the action of physical activity on established CVD risk factors, such as levels of blood pressure or lipids ${ }^{2}$. There is also some evidence, although less abundant, that physical activity is associated with eating habits conferring protection towards CVD, such as higher intakes of fruits and vegetables ${ }^{3-8}$.

Habitual physical activity is usually defined as any bodily movement produced by the contraction of skeletal muscle and that substantially increases energy expenditure ${ }^{1}$. Based upon the context in which physical activity occurs, common domains are leisure-time (including sports) and occupational physical activity ${ }^{9}$. Whereas early studies on physical activity and CVD assessed physical activity at work, most subsequent research has focused on leisure activity, often assumed to best represent physical activity in a population 9 . Current public health recommendations emphasise the importance of physical activity accumulated in the various settings of daily living, including leisure and sports, occupational and transport or home physical activity ${ }^{1}$.

Recent data about occupational physical activity (OPA) in relation with CVD risk provide mixed results, some studies showing no relationship ${ }^{10}$ and others an inverse association $^{11}$ with CVD mortality. An intriguing finding is that some of the studies that documented inverse (i.e. 
favourable) associations between leisure-time physical activity (LTPA) and CVD risk factors such as body mass index (BMI), blood pressure or lipid levels also found concurrent positive (i.e. unfavourable) or non-significant associations between OPA and the same risk factors ${ }^{12-19}$. In this context, few recent studies have explored the relationships of both LTPA and OPA with eating habits that might protect against $\mathrm{CVD}^{6}$.

The aim of the present study was to investigate the relationships of LTPA (including sports) and OPA with (1) several clinical and biological CVD risk factors and (2) eating habits in French adults seen in a preventive medicine setting.

\section{Methods}

\section{Subjects and setting}

Subjects were examined at the Centre d'investigations préventives et cliniques (IPC Centre, Paris, France), a preventive medicine centre subsidised by the French national health care system (Caisse Nationale d'Assurance Maladie), which provides free medical examinations on a 5-year basis for all working and retired persons and their families. Since 1970, this centre has carried out approximately 20000-25000 examinations per year for people living in the Paris area ${ }^{20}$. Consecutive subjects examined at the IPC Centre between June and September 2001 were asked to participate in this study. Acceptance rate was 91\%. After excluding pregnant women $(n=13)$, data from 5478 subjects (3737 men and 1741 women) aged 20-80 years were available for analysis.

Sociodemographic characteristics of the subjects were assessed using a standardised self-administered questionnaire ${ }^{20}$. Educational level was coded into three categories according to the highest certification obtained (below high school, between high school and 2-year college, college graduate or higher). Data on smoking status (current, former or never smoker) and alcohol intake $\left(\leq 20 \mathrm{~g} \mathrm{day}^{-1}\right.$ or $>20 \mathrm{~g} \mathrm{day}^{-1}$ according to the number of drinks per day) were collected using the same questionnaire. The study protocol was approved by a national ad boc committee, the Commission Nationale de l'Informatique et des Libertés. At the time of examination, all subjects gave their informed written consent to have their data used for epidemiological studies.

\section{Assessment of physical activity and eating habits}

Physical activity was assessed using the Baecke questionnaire $^{21}$. This questionnaire assesses the habitual level of physical activity according to the setting in which it occurs, as described in detail elsewhere ${ }^{21,22}$. Briefly, it consists of 16 questions organised in three sections: physical activity at work (questions 1 to 8), sport during leisure time (questions 9 to 12) and physical activity during leisure time excluding sport (questions 12 to 16). Questions in each section are scored on a five-point Likert scale, ranging from never to always or very often. For the most frequently reported sports activities, additional questions query the number of months per year and hours per week of participation. The three derived indices, work, sports and non-sports leisure, are scored in arbitrary units ranging from 1 to 5 . In this report, OPA refers to results for the work index and LTPA refers to results for the sum of sports and non-sports leisure indices.

The Baecke questionnaire has been used in a number of studies in various populations and its properties (validity, reliability) have been tested ${ }^{22}$. In a study in 19 Dutch male subjects aged 40 years, the correlation coefficient between total activity (sum of work, sports and non-sports leisure) and average daily energy expenditure measured by the doubly-labelled water technique was $0.62^{23}$. The sports and non-sports leisure indices of the French version of the Baecke questionnaire have been evaluated for validity using maximal aerobic capacity $\left(\dot{\mathrm{V}} \mathrm{O}_{2 \max }\right)$ as criterion ${ }^{24}$ : in 118 male subjects aged 30-58 years, correlation coefficients were 0.53 for the sports index and 0.44 for the leisure index (both $P<0.001$ ). In the original publication by Baecke et $a l .^{21}$, in 139 men and 167 females aged 20 to 32 years, 3-month repeatability coefficients were $0.88,0.81$ and 0.74 for work, sport and leisure indices, respectively. In 78 men and women aged 20-59 years, age- and sexadjusted correlation coefficients for 1-month test-retest repeatability were $0.78,0.90$ and 0.86 for work, sport and leisure indices, respectively ${ }^{25}$; sex-specific correlation coefficients were 0.92 in men and 0.90 in women for leisure-time activity (sum of sports and non-sports leisure) $)^{26}$

Habitual food intakes were assessed using an adapted version of a short self-reported food-frequency questionnaire, the NAQA (18 items), designed for use in preventive medicine centres in France ${ }^{27}$. Questions used in the present paper pertained to the composition of the habitual breakfast (continental breakfast, English breakfast, nothing or only a beverage), the amount of meat eaten per day (less than $100 \mathrm{~g}_{\text {day }}{ }^{-1}$, between 100 and $200 \mathrm{~g} \mathrm{day}^{-1}$, more than $200 \mathrm{~g} \mathrm{day}^{-1}$ ), the weekly frequency of eating fish, fresh fruit and vegetables (for each item: less than 2 times week ${ }^{-1}$, between 2 and 4 times week ${ }^{-1}$, more than 4 times week ${ }^{-1}$ ). This questionnaire has been used in epidemiological settings similar to ours ${ }^{28}$ and validated versus face-to-face interview with the dietary history $\operatorname{method}^{27}$. In that study among 250 men and 250 women aged 17 to 60 years seen for a health check-up at a preventive medicine centre in Tours, France, correlation coefficients between the methods ranged between 0.49 and 0.80 for energy and macronutrient intakes ${ }^{27}$.

\section{Assessment of CVD risk factors}

Anthropometric and body composition data were collected with subjects in indoor clothing and no shoes. 
Height was measured to the nearest $0.5 \mathrm{~cm}$ with a wallmounted stadiometer. Bioelectrical impedance analysis was used to assess body fat percentage, using a bipodal device with inbuilt scales measuring body weight at the same time (Tanita TBF-310; Tanita Corp., Tokyo, Japan) ${ }^{29}$. Assessment of body composition by the foot-to-foot Tanita device has been shown to give similar results to the more traditional foot-to-arm devices ${ }^{29}$. BMI was calculated as body weight divided by the square of height $\left(\mathrm{kg} \mathrm{m}^{-2}\right)$. Waist circumference, as an indicator of abdominal fat, was measured using an inelastic tape as the circumference midway between the lower rib and the iliac crest on the mid-axillary line. Supine blood pressure was measured by a nurse in the right arm using a manual mercury sphygmomanometer, after a 10-min rest period. The first and fifth Korotkoff phases were used to define systolic and diastolic blood pressure. Resting heart rate was measured with a standard 12-lead electrocardiogram. Biological measurements were performed on venous blood samples collected after a $12 \mathrm{~h}$ fast using standard methods (Technicon SMA 12, Hitachi, France).

\section{Analyses}

Since physical activity patterns and levels of CVD risk factors differed between genders, all analyses were performed separately in men and women. Betweengender comparisons were performed by $t$-tests for continuous variables and by chi-square tests for categorical variables. Sex-specific quartiles of leisure-time and occupational physical activity scores were defined. Relationships of LTPA and OPA with each CVD risk factor were assessed using multivariate analysis of variance. Relationships of LTPA and OPA with eating habits were assessed using multivariate logistic regression analysis. In both procedures, adjustments were performed for age, then for age and educational level, to investigate how this socio-economic indicator may affect the associations between physical activity and CVD risk factors or eating habits. Further adjustment for OPA was performed in analyses with LTPA, and for LTPA in analyses with OPA. Additionally, smoking status and alcohol consumption were adjusted for. For eating habits, results from the logistic regression analyses are presented as odds ratios and their 95\% confidence intervals. The lowest physical activity quartile was used as the reference category. Interaction factors were considered in order to evaluate possible heterogeneity in the associations between physical activity and CVD risk factors or eating habits across levels of other factors such as educational level. For continuous variables, general descriptive data are presented as mean and standard deviation (SD), data from multivariate models are presented as mean and standard error of the mean (SEM). The SAS statistical package (version 6.12; SAS Institute, Cary, NC, USA) was used for all analyses.

\section{Results}

Table 1 shows the characteristics of the study subjects. A majority of subjects were in the age range 30-59 years: $82 \%$ in men, $69 \%$ in women. Based on BMI $\geq 30 \mathrm{~kg} \mathrm{~m}^{-2}$, $9.9 \%$ of men and $8.4 \%$ of women were obese $(P=0.10$ for between-gender comparison). In men and women respectively, $30.5 \%$ and $25.6 \%$ were current smokers, $40.9 \%$ and $58.6 \%$ were never smokers $(P<0.001$ for between-gender comparison). For physical activity, 56\% of men engaged in at least one sport compared with $49 \%$ of women ( $P<0.0001$ for between-gender comparison). In men and women, $20.3 \%$ and $38.2 \%$ of subjects, respectively, reported having no professional occupation for the past 6 months $(P<0.0001$ for between-gender comparison). For physical activity scores, the sport index and the total LTPA index (sum of sports and non-sports activities) were significantly higher in men than women $(P<0.0001)$. In both genders, scores for OPA did not differ significantly across quartiles of LTPA (men: 2.48 (0.02), 2.53 (0.02), 2.56 (0.02), 2.56 (0.02); women: 2.47 (0.02), 2.58 (0.04), 2.55 (0.04), 2.59 (0.04); mean (SEM)). For alcohol consumption, $8.9 \%$ of men and $18.8 \%$ of women did not drink alcohol, $65.2 \%$ of men and $73.8 \%$ of women consumed less than $20 \mathrm{~g} \mathrm{day}^{-1}$, and $25.9 \%$ of men and $7.4 \%$ of women drank more than $20 \mathrm{~g}_{\text {day }}{ }^{-1}$.

For LTPA, when adjusted for age only, significant $(P=0.0001)$ negative associations were observed in both genders with BMI, body fat percentage, waist circumference, resting heart rate, diastolic blood pressure and triglycerides, whereas a positive association was found with high-density lipoprotein cholesterol (HDL-C); a negative association was found with systolic blood pressure in women $(P=0.0002)$ but not in men $(P=0.61)$; in both genders, no significant association was found with fasting blood glucose. With further adjustment for educational level, the same trends were observed in both genders (Table 2). After further adjustment for OPA, smoking status and alcohol consumption, these relationships were unaltered (data not shown).

For OPA, when adjusted for age only, significant positive relationships were observed with BMI (men: $P=0.002$; women: $P=0.003$ ), body fat percentage (men: $P=0.02$; women: $P=0.03)$, waist circumference in women $(P=0.0006)$, systolic and diastolic blood pressure in men $(P=0.0007$ and $P=0.02$, respectively), and resting heart rate in men $(P=0.004)$. With further adjustment for educational level, the only positive relationship that remained significant was with waist circumference in women (Table 3). Essentially the same results were found after further adjustment for LTPA, smoking status and alcohol consumption (data not shown).

Analyses of the relationships of LTPA and OPA (in quartiles) with eating habits were performed following 
Table 1 Characteristics of the subjects

\begin{tabular}{|c|c|c|c|}
\hline & Men $(n=3737)$ & Women $(n=1741)$ & $P$ \\
\hline Age (years) & $46.1(11.0)$ & $46.3(13.0)$ & 0.58 \\
\hline Body mass index $\left(\mathrm{kg} \mathrm{m}^{-2}\right)$ & $25.6(3.5)$ & $23.7(4.3)$ & $<0.0001$ \\
\hline Body fat percentage & $21.2(5.8)$ & $29.4(7.9)$ & $<0.0001$ \\
\hline Waist circumference $(\mathrm{cm})$ & $90.5(9.9)$ & $76.7(10.1)$ & $<0.0001$ \\
\hline \multicolumn{4}{|l|}{ Educational level (\%) } \\
\hline$<$ Junior high school & 27.6 & 34.9 & \multirow[t]{3}{*}{$<0.001$} \\
\hline$<2$-year college & 29.3 & 36.7 & \\
\hline$>$ College graduate & 43.1 & 28.4 & \\
\hline \multicolumn{4}{|l|}{ Physical activity scores } \\
\hline Sport index (1) & $2.64(0.76)$ & $2.33(0.75)$ & $<0.0001$ \\
\hline Non-sport leisure index (2) & $2.77(0.62)$ & $2.79(0.63)$ & 0.27 \\
\hline Leisure-time physical activity $(1+2)$ & $5.45(1.08)$ & $5.18(1.13)$ & $<0.0001$ \\
\hline Work index (occupational physical activity) (3) & $2.55(0.70)$ & $2.57(0.69)$ & 0.32 \\
\hline \multicolumn{4}{|l|}{ Eating habits $(\%)$} \\
\hline Complete breakfast & 70.5 & 77.1 & $<0.0001$ \\
\hline Meat $>200 \mathrm{~g} \mathrm{day}^{-1}$ & 7.2 & 5.0 & 0.002 \\
\hline Fish $>4$ times week $^{-1}$ & 3.3 & 4.3 & 0.053 \\
\hline Vegetables $>4$ times week $^{-1}$ & 37.8 & 53.5 & $<0.0001$ \\
\hline Fresh fruit $>4$ times week ${ }^{-1}$ & 38.7 & 53.0 & $<0.0001$ \\
\hline Systolic blood pressure (mmHg) & $134(18)$ & $127(20)$ & $<0.0001$ \\
\hline Diastolic blood pressure $(\mathrm{mmHg})$ & $80(12)$ & $75(12)$ & $<0.0001$ \\
\hline Resting heart rate (beats $\min ^{-1}$ ) & $61.6(10.3)$ & $64.0(9.8)$ & $<0.0001$ \\
\hline Fasting plasma glucose $\left(\mathrm{g} \mathrm{I}^{-1}\right)$ & $0.98(0.14)$ & $0.92(0.12)$ & $<0.0001$ \\
\hline Total cholesterol $\left(\mathrm{g} \mathrm{I}^{-1}\right)$ & $2.20(0.42)$ & $2.14(0.41)$ & $<0.0001$ \\
\hline High-density lipoprotein cholesterol $\left(\mathrm{g} \mathrm{I}^{-1}\right)$ & $0.62(0.16)$ & $0.78(0.19)$ & $<0.0001$ \\
\hline Triglycerides $\left(\mathrm{g} \mathrm{I}^{-1}\right)$ & $1.14(0.89)$ & $0.81(0.50)$ & $<0.0001$ \\
\hline
\end{tabular}

Values for quantitative variables are means (standard deviation). Comparison between genders was performed by $t$-tests (quantitative variables) or chi-square tests (qualitative variables).

the same successive steps for adjustment. In both genders, results for LTPA were not substantially modified after adjustment for educational level in addition to age. As shown in Table 4, subjects in higher quartiles of LTPA were more likely to eat a complete breakfast as well as fruits and vegetables more than 4 times per week, and less likely to eat more than $200 \mathrm{~g}$ of meat per day. The same pattern was found after further adjustment for OPA, smoking status and alcohol consumption (data not shown). For OPA, with adjustment on age and educational level, the only significant trends observed were, in women, a decreased likelihood for eating a complete breakfast and an increased likelihood for eating more than $200 \mathrm{~g}$ of meat per day in higher quartiles of OPA (data not shown). Additional adjustment for LTPA, smoking status and alcohol consumption did not alter these results.

Associations of LTPA and OPA with CVD risk factors and eating habits were also analysed after stratification by educational level. No significant interaction was found with educational level in the relationships between physical activity and CVD risk factors or eating habits (data not shown).

\section{Discussion}

The results of this study document that, in French adults of both genders, relationships of physical activity with several markers of CVD risk and eating habits differ markedly according to the setting in which physical activity takes place. The data emphasise LTPA as an important health behaviour in relation to CVD risk, independently of educational level and physical demand at work. Contrasting with results on LTPA, ageadjusted data for OPA were related in an unfavourable way to CVD risk factors; however, most of these associations were no longer significant after taking account of educational level.

In agreement with several previous reports, LTPA and OPA activity were consistently differently associated with indicators of overall corpulence such as $\mathrm{BMI}^{14,16-19}$, indicators of body fat distribution such as waist circumference ${ }^{14,17,18}$, resting heart rate $\mathrm{r}^{17,18}$, diastolic blood pressure ${ }^{12,17}$, triglycerides ${ }^{18}$ and HDL-C ${ }^{16}$. In some other reports, however, low levels of both LTPA and OPA were related to increased levels of risk factors such as blood pressure ${ }^{30}$, lipids ${ }^{31}$ or BMI (in women) ${ }^{32}$. Differences in study populations, in trends over time in CVD risk factors and related lifestyle variables ${ }^{32}$ and in assessments of habitual physical activity may partly explain these discrepancies. Results were more heterogeneous for systolic blood pressure. Other studies suggest that the relationships of habitual physical activity during leisure with blood pressure may be less consistent than associations with biological risk factors such as triglycerides and HDL-C concentrations ${ }^{18,33}$.

In contrast to most previous studies which each focused on a rather limited number of CVD risk factors, we assessed a large panel of CVD risk markers, including body fat as evaluated by bioimpedance 
Table 2 Mean (standard error of the mean)* cardiovascular risk factors according to quartile of leisure-time physical activity

\begin{tabular}{|c|c|c|c|c|c|}
\hline & Q1† & Q2 & Q3 & Q4 & $P \ddagger$ \\
\hline \multicolumn{6}{|l|}{ Men } \\
\hline$n$ & 805 & 906 & 922 & 943 & \\
\hline Quartile limits & $2.25-4.50$ & $4.75-5.25$ & $5.50-6.00$ & $6.25-9.75$ & \\
\hline Age (years) & $45.2(10.7)$ & $46.0(11.0)$ & $46.4(11.0)$ & $46.3(11.2)$ & - \\
\hline Body mass index $\left(\mathrm{kg} \mathrm{m}^{-2}\right)$ & $26.1(0.1)$ & $25.4(0.1)$ & $25.4(0.1)$ & $25.3(0.1)$ & 0.0001 \\
\hline Body fat percentage & $22.5(0.2)$ & $21.2(0.2)$ & $20.9(0.2)$ & $20.4(0.2)$ & 0.0001 \\
\hline Waist circumference $(\mathrm{cm})$ & $92.9(0.3)$ & $90.8(0.3)$ & $89.7(0.3)$ & $89.1(0.3)$ & 0.0001 \\
\hline Systolic blood pressure (mmHg) & $135.0(0.6)$ & $134.0(0.6)$ & $134.0(0.6)$ & $134.0(0.6)$ & 0.45 \\
\hline Diastolic blood pressure $(\mathrm{mmHg})$ & $81.0(0.4)$ & $80.0(0.4)$ & $80.0(0.4)$ & $79.0(0.4)$ & 0.005 \\
\hline Resting heart rate (beats $\min ^{-1}$ ) & $64.0(0.4)$ & $62.9(0.4)$ & $60.8(0.3)$ & $59.0(0.3)$ & 0.0001 \\
\hline Fasting plasma glucose $\left(\mathrm{g} \mathrm{I}^{-1}\right)$ & $0.99(0.01)$ & $0.99(0.01)$ & $0.98(0.01)$ & $0.98(0.01)$ & 0.35 \\
\hline Total cholesterol $\left(\mathrm{g} \mathrm{I}^{-1}\right)$ & $2.22(0.01)$ & $2.19(0.01)$ & $2.21(0.01)$ & $2.17(0.01)$ & 0.05 \\
\hline High-density lipoprotein cholesterol $\left(\mathrm{g} \mathrm{I}^{-1}\right)$ & $0.60(0.01)$ & $0.62(0.01)$ & $0.63(0.01)$ & $0.65(0.01)$ & 0.0001 \\
\hline Triglycerides $\left(\mathrm{g} \mathrm{I}^{-1}\right)$ & $1.25(0.03)$ & $1.17(0.03)$ & $1.14(0.03)$ & $1.01(0.03)$ & 0.0001 \\
\hline \multicolumn{6}{|l|}{ Women } \\
\hline$n$ & 398 & 391 & 391 & 424 & \\
\hline Quartile limits & $2.25-4.25$ & $4.50-5.00$ & $5.25-5.75$ & $6.00-8.75$ & \\
\hline Age (years) & $46.3(12.9)$ & $45.5(13.1)$ & 46.5 (13.2) & $44.8(12.3)$ & - \\
\hline Body mass index $\left(\mathrm{kg} \mathrm{m}^{-2}\right)$ & $24.5(0.2)$ & $23.7(0.2)$ & $23.3(0.2)$ & $22.8(0.2)$ & 0.0001 \\
\hline Body fat percentage & $30.6(0.4)$ & $29.6(0.4)$ & $28.8(0.4)$ & $27.8(0.4)$ & 0.0001 \\
\hline Waist circumference (cm) & $78.3(0.5)$ & $76.8(0.5)$ & $75.5(0.5)$ & $74.8(0.5)$ & 0.0001 \\
\hline Systolic blood pressure (mmHg) & $129.0(0.9)$ & $126.0(0.9)$ & $126.0(0.9)$ & $124.0(0.9)$ & 0.002 \\
\hline Diastolic blood pressure $(\mathrm{mmHg})$ & $76.0(0.6)$ & $75.0(0.6)$ & $74.0(0.6)$ & $73.0(0.6)$ & 0.0005 \\
\hline Resting heart rate (beats $\min ^{-1}$ ) & $65.3(0.5)$ & $64.9(0.5)$ & $63.5(0.5)$ & $61.7(0.5)$ & 0.0001 \\
\hline Fasting plasma glucose $\left(\mathrm{g} \mathrm{I}^{-1}\right)$ & $0.93(0.01)$ & $0.92(0.01)$ & $0.91(0.01)$ & $0.91(0.01)$ & 0.07 \\
\hline Total cholesterol $\left(\mathrm{g} \mathrm{I}^{-1}\right)$ & $2.16(0.02)$ & $2.10(0.02)$ & $2.10(0.02)$ & $2.15(0.02)$ & 0.04 \\
\hline High-density lipoprotein cholesterol $\left(\mathrm{g} \mathrm{I}^{-1}\right)$ & $0.73(0.01)$ & $0.78(0.01)$ & $0.78(0.01)$ & $0.82(0.01)$ & 0.0001 \\
\hline Triglycerides $\left(\mathrm{g} \mathrm{I}^{-1}\right)$ & $0.93(0.02)$ & $0.78(0.02)$ & $0.77(0.02)$ & $0.74(0.02)$ & 0.0001 \\
\hline
\end{tabular}

*Means adjusted for age and educational level.

tQ1 to Q4 are sex-specific quartiles.

$\ddagger P$-value for analysis of variance ( $P$ for trend).

analysis. We used a physical activity questionnaire designed to assess various dimensions of habitual physical activity, which in particular may improve assessment of OPA compared with rather crude evaluations based on type of occupation or job title. It should also be noted that a number of previous reports were only in men ${ }^{12-14}$. Our results indicate that similar differential relationships of LTPA and OPA with CVD risk factors are found in both genders, although the data show the known gender differences in physical activity patterns (with women generally less active than men) $)^{1,34}$ and CVD risk factors (with women generally having lower levels of major risk factors $)^{35}$.

We observed that LTPA, but not OPA, was associated with eating habits that may protect against CVD, such as more frequent intake of fruits and vegetables, more frequent intake of fish (in men) and less frequent intake of meat ${ }^{36,37}$. Similar relationships with eating habits were reported in a few studies that dealt with LTPA only in populations from the USA ${ }^{3,4,7}$, Germany ${ }^{5}$ and Spain ${ }^{8}$. French data with which we could compare our results are scarce. In middle-aged French men included in the PRIME (Prospective Epidemiological Study of Myocardial Infarction) cohort, increased frequency of vegetable and fruit consumption as well as fish consumption was found to be associated with energy expended during $\mathrm{LTPA}^{38}$. In a recent study where OPA and LTPA were concurrently assessed, heavy manual work in adults from the Spanish EPIC (European Prospective Investigation into Cancer and Nutrition) cohort was found to be positively associated with fruit and vegetable intake ${ }^{6}$, pointing to the need for further investigation of this issue in various populations. In the present study, subjects in the highest quartiles of LTPA were also more likely to have a breakfast that was not limited to a beverage. Being active during leisure time was associated with regular breakfast habit in one German study $^{5}$. Although most of our subjects eating breakfast regularly consumed a 'continental' type of breakfast (data not shown), it is interesting to note that whole-grain breakfast cereal intakes were recently shown to be inversely associated with CVD mortality in the Nurses' Health Study ${ }^{39}$. Overall, the specific dimension of physical activity during leisure time, in contrast with physical activity at work, appeared to be associated with a healthier food intake pattern. This is in line with studies in adult populations showing that LTPA tends to cluster with other health-related behaviours including so-called 'prudent' dietary patterns ${ }^{40}$.

In this study, most relationships of OPA with CVD risk factors were no longer significant when adjustment on educational level was performed in addition to age. This suggests that socio-economic status, as assessed by educational attainment, accounts at least in part for the unfavourable associations of physical activity at work with 
Table 3 Mean (standard error of the mean) ${ }^{\star}$ cardiovascular risk factors according to quartile of occupational physical activity

\begin{tabular}{|c|c|c|c|c|c|}
\hline & Q1† & Q2 & Q3 & Q4 & $P \neq$ \\
\hline \multicolumn{6}{|l|}{ Men } \\
\hline$n$ & 792 & 891 & 636 & 781 & \\
\hline Quartile limits & $1.00-2.00$ & $2.14-2.43$ & $2.57-2.86$ & $3.00-5.00$ & \\
\hline Age (years) & $45.1(9.4)$ & $45.3(9.5)$ & $44.3(9.5)$ & $42.9(9.9)$ & - \\
\hline Body mass index $\left(\mathrm{kg} \mathrm{m}^{-2}\right)$ & $25.4(0.1)$ & $25.6(0.1)$ & $25.4(0.1)$ & $25.7(0.1)$ & 0.44 \\
\hline Body fat percentage & $21.0(0.2)$ & $21.1(0.2)$ & $20.9(0.2)$ & $21.2(0.2)$ & 0.79 \\
\hline Waist circumference $(\mathrm{cm})$ & $90.3(0.3)$ & $90.6(0.3)$ & $90.4(0.4)$ & $90.3(0.4)$ & 0.94 \\
\hline Systolic blood pressure (mmHg) & $133.0(0.6)$ & $133.0(0.6)$ & $133.0(0.7)$ & $134.0(0.7)$ & 0.75 \\
\hline Diastolic blood pressure $(\mathrm{mmHg})$ & $79.0(0.4)$ & $80.0(0.4)$ & $80.0(0.5)$ & $80.0(0.4)$ & 0.69 \\
\hline Resting heart rate (beats $\min ^{-1}$ ) & $60.8(0.4)$ & $61.3(0.3)$ & $61.9(0.4)$ & $61.5(0.4)$ & 0.24 \\
\hline Fasting plasma glucose $\left(\mathrm{g} \mathrm{I}^{-1}\right)$ & $0.98(0.01)$ & $0.98(0.01)$ & $0.98(0.01)$ & $0.98(0.01)$ & 0.92 \\
\hline Total cholesterol $\left(\mathrm{g} \mathrm{I}^{-1}\right)$ & $2.19(0.01)$ & $2.22(0.01)$ & $2.19(0.02)$ & $2.18(0.02)$ & 0.26 \\
\hline High-density lipoprotein cholesterol $\left(\mathrm{g} \mathrm{I}^{-1}\right)$ & $0.63(0.01)$ & $0.62(0.01)$ & $0.62(0.01)$ & $0.62(0.01)$ & 0.94 \\
\hline Triglycerides $\left(\mathrm{g} \mathrm{l}^{-1}\right)$ & $1.15(0.03)$ & $1.15(0.03)$ & $1.11(0.04)$ & $1.12(0.04)$ & 0.82 \\
\hline \multicolumn{6}{|l|}{ Women } \\
\hline$n$ & 278 & 313 & 248 & 295 & \\
\hline Quartile limits & $1.14-2.00$ & $2.14-2.42$ & $2.57-2.86$ & $3.00-5.00$ & \\
\hline Age (years) & $44.0(10.3)$ & $41.1(10.1)$ & $42.4(10.3)$ & $41.6(10.9)$ & - \\
\hline Body mass index $\left(\mathrm{kg} \mathrm{m}^{-2}\right)$ & $23.1(0.3)$ & $23.0(0.2)$ & $23.5(0.3)$ & $23.9(0.2)$ & 0.07 \\
\hline Body fat percentage & $28.3(0.5)$ & $28.0(0.4)$ & $28.6(0.5)$ & $29.3(0.4)$ & 0.18 \\
\hline Waist circumference (cm) & $74.8(0.6)$ & $75.3(0.5)$ & $75.3(0.6)$ & $77.0(0.5)$ & 0.03 \\
\hline Systolic blood pressure (mmHg) & $123.0(1.1)$ & $122.0(1.0)$ & $124.0(1.1)$ & $124.0(1.0)$ & 0.55 \\
\hline Diastolic blood pressure $(\mathrm{mmHg})$ & $73.0(0.7)$ & $73.0(0.7)$ & $73.0(0.7)$ & $75.0(0.7)$ & 0.38 \\
\hline Resting heart rate (beats $\min ^{-1}$ ) & $62.4(0.6)$ & $63.5(0.5)$ & $64.4(0.6)$ & $63.3(0.6)$ & 0.11 \\
\hline Fasting plasma glucose $\left(\mathrm{g} \mathrm{I}^{-1}\right)$ & $0.91(0.01)$ & $0.91(0.01)$ & $0.91(0.01)$ & $0.91(0.01)$ & 0.78 \\
\hline Total cholesterol $\left(\mathrm{g} \mathrm{I}^{-1}\right)$ & $2.09(0.02)$ & $2.07(0.02)$ & $2.07(0.02)$ & $2.09(0.02)$ & 0.83 \\
\hline High-density lipoprotein cholesterol $\left(\mathrm{g} \mathrm{I}^{-1}\right)$ & $0.77(0.01)$ & $0.77(0.01)$ & $0.77(0.01)$ & $0.76(0.01)$ & 0.95 \\
\hline Triglycerides $\left(\mathrm{g} \mathrm{I}^{-1}\right)$ & $0.76(0.02)$ & $0.77(0.02)$ & $0.76(0.02)$ & $0.82(0.02)$ & 0.28 \\
\hline
\end{tabular}

*Means adjusted for age and educational level.

tQ1 to Q4 are sex-specific quartiles.

$\ddagger P$-value for analysis of variance ( $P$ for trend).

the panel of CVD risk factors examined. Such influence of educational level has been examined specifically in previous studies for outcomes such as BMI or indicators of body fat distribution ${ }^{14,41}$. In a study by Baecke et ll $^{41}$ in young Dutch adults, OPA using their questionnaire was positively associated with BMI but the strength of the association was largely diminished when adjusting for educational level. Using the same questionnaire, a positive (though non-significant) association of work activity with waist-to-hip ratio was very much reduced after taking into account educational level in European men aged 38 years studied by Seidell et al. ${ }^{14}$. The fact that waist circumference remained positively associated with OPA after multivariable adjustment could reflect a remaining effect of socio-economic status not captured by taking into account educational level. Educational level is known as a strong CVD predictor ${ }^{42}$ and is also a correlate of habitual physical activity levels, as we previously showed in French adults for LTPA $^{34,38}$. There is evidence that indicators of social class are positively related to LTPA and negatively related to

Table 4 Odds ratio (95\% confidence interval)* for eating habits according to quartile of leisure-time physical activity

\begin{tabular}{|c|c|c|c|c|}
\hline & Q1† & Q2 & Q3 & Q4 \\
\hline \multicolumn{5}{|l|}{ Men } \\
\hline 1. Breakfast with more than only a beverage & 1.00 & $1.45(1.18-1.77)$ & $1.93(1.56-2.39)$ & $2.42(1.95-3.00)$ \\
\hline 2. Meat $>200 \mathrm{~g} \mathrm{day}^{-1}$ & 1.00 & $0.75(0.53-1.07)$ & $0.49(0.33-0.72)$ & $0.68(0.48-0.97)$ \\
\hline 3. Fish $>4$ times week $^{-1}$ & 1.00 & $1.24(0.69-2.25)$ & $1.42(0.79-2.54)$ & $1.74(1.00-3.03)$ \\
\hline 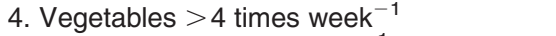 & 1.00 & $1.22(0.99-1.50)$ & $1.64(1.34-2.01)$ & $1.81(1.48-2.21)$ \\
\hline 5. Fresh fruit $>4$ times week ${ }^{-1}$ & 1.00 & $1.18(0.96-1.46)$ & $1.59(1.29-1.96)$ & $2.05(1.68-2.52)$ \\
\hline \multicolumn{5}{|l|}{ Women } \\
\hline 1. Breakfast with more than only a beverage & 1.00 & $2.03(1.46-2.83)$ & $2.81(1.97-4.00)$ & $2.97(2.09-4.21)$ \\
\hline 2. Meat $>200 \mathrm{~g} \mathrm{day}^{-1}$ & 1.00 & $0.79(0.44-1.43)$ & $0.76(0.42-1.39)$ & $0.39(0.19-0.80)$ \\
\hline 3. Fish $>4$ times week $^{-1}$ & 1.00 & $1.12(0.52-2.42)$ & $1.55(0.76-3.17)$ & $1.02(0.47-2.22)$ \\
\hline 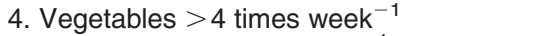 & 1.00 & $1.14(0.86-1.53)$ & $1.45(1.09-1.93)$ & $2.22(1.66-2.97)$ \\
\hline 5. Fresh fruit $>4$ times week $^{-1}$ & 1.00 & $1.03(0.77-1.39)$ & $1.21(0.91-1.62)$ & $1.90(1.41-2.55)$ \\
\hline
\end{tabular}

*Odds ratios from multivariate regression models with age and educational level.

†Q1 to Q4 are sex-specific quartiles (see Table 2). 
$\mathrm{OPA}^{13,30}$. However, mediators of the effect of socioeconomic position on the OPA-CVD risk factors relationships would need further delineation. Psychosocial stress and job strain (high demand, low control) in certain occupations, especially those requiring low education, were shown to be adversely associated with cardiovascular health ${ }^{43}$.

Several other issues may be considered to explain the differential associations of LTPA and OPA with CVD risk factors and eating habits under study. First, a limited range of activity levels across most current professional occupations may have obscured any association with physical activity at work. However, SDs for the Baecke work index in the present study were of about the same magnitude as those for the leisure and sport indices. Second, the validity of the work index of the Baecke questionnaire appears lower than the other indices when measures of physical fitness, e.g. aerobic capacity $\left(\dot{\mathrm{V}} \mathrm{O}_{2 \max }\right)$, are used as criterion $^{25}$. Our data for resting heart rate as a surrogate marker for physical fitness may support this notion. We found resting heart rate was negatively associated with LTPA but OPA, in agreement with previous reports ${ }^{17}$. Third, characteristics of physical activity at work, mainly long lasting and static, differ from most activities performed during leisure, mainly short lasting and dynamic ${ }^{13,44}$, and may result in different effects on the level of CVD risk factors as well as eating habits. For example, LTPA, when vigorous, could stimulate the sympathetic nervous system and induce a negative energy or fat balance through activation of skeletal muscle metabolism, whereas OPA could favour a positive energy or fat balance by stress activation of the hypothalamic-pituitary-adrenal axis and glucocorticoids, resulting in increased appetite and food intake $^{45,46}$. Moreover, different aspects of OPA itself may have different influences, as suggested recently ${ }^{47}$. In a case-control study, it was shown that walking at work, considered an aerobic activity, was associated with a decreased risk of myocardial infarction, whereas heavy lifting at work, regarded as mainly anaerobic activity, was associated with an increased risk ${ }^{47}$.

The present study has a cross-sectional design, thus it is not possible to conclude on causality. Subjects were mostly middle-aged relatively highly educated adults, seen in a preventive medicine centre for a free medical examination in Paris, France. However, the distribution of educational categories was close to data for the Paris area from the French National Institute of Statistics and Economic Studies (Institut National de la Statistique et des Etudes Economiques, Paris, France; www.insee.fr). When using the Baecke questionnaire, physical activity variables are expressed in arbitrary units, therefore limiting discussions about dose-response issues in terms of respective relationships of moderate and vigorous activity on health outcomes $^{1}$. Also, the summary indices derived from this questionnaire do not allow to study in detail domains of habitual physical activity such as home or transport physical activity, which have been inversely associated with CVD risk factors ${ }^{48,49}$. Recall bias is inherent to selfreported questionnaires and some misclassifications may have occurred both for physical activity and eating habits. It is known that self-reported measures of physical activity are likely to contain errors of overreporting ${ }^{1,22}$. Finally, eating habits were assessed using a simplified food-frequency questionnaire, and this did not allow us to analyse in detail the influence of dietary intakes on the relationships of physical activity with CVD risk factors.

In conclusion, results of this study strongly underline the favourable associations of physical activity during leisure time with a large set of markers of CVD risk and with some healthy eating habits known as protective against CVD. Importantly, these relationships were observed in both genders, independent of socio-economic status as reflected by educational level, and independent of physical activity at work. Leisure physical activity is a modifiable health behaviour. In the development and implementation of intervention programmes and public health policies designed to increase physical activity to recommended levels in similar populations, the practical implications of our findings are that LTPA remains a major target behaviour. Further investigation of social and behavioural, especially dietary, factors that could explain the less favourable relationships of OPA with cardiovascular outcomes seems warranted, together with consideration of other types of physical activity not specifically taken into account here, such as commuting and homerelated physical activity.

\section{Acknowledgements}

This study was supported, in part, by a grant from the French Ministry of Research and Technology (MRT, AQS2001-N40) and by an unrestricted research grant from Masterfoods Inc. B De Clercq is gratefully acknowledged for assistance with data collection.

\section{References}

1 US Department of Health and Human Services (DHSS). Physical Activity and Health: A Report of the Surgeon General. Atlanta, GA: US DHSS, Centers for Disease Control and Prevention, National Center for Chronic Disease Prevention and Health Promotion, 1996.

2 Wannamethee SG, Shaper AG. Physical activity in the prevention of cardiovascular disease: an epidemiological perspective. Sports Medicine 2001; 31: 101-14.

3 Eaton CB, McPhillips JB, Gans KM, Garber CE, Assaf AR, Lasater TM, et al. Cross-sectional relationship between diet and physical activity in two southeastern New England communities. American Journal of Preventive Medicine 1995; 11: 238-44.

4 Matthews CE, Hebert JR, Ockene IS, Saperia G, Merriam PA. Relationship between leisure-time physical activity and selected dietary variables in the Worcester Area Trial for Counseling in Hyperlipidemia. Medicine and Science in Sports and Exercise 1997; 29: 1199-207. 
5 Mensink GB, Loose N, Oomen CM. Physical activity and its association with other lifestyle factors. European Journal of Epidemiology 1997; 13: 771-8.

6 Agudo A, Pera G. Vegetable and fruit consumption associated with anthropometric, dietary and lifestyle factors in Spain. EPIC Group of Spain. European Prospective Investigation into Cancer. Public Health Nutrition 1999; 2: 263-71.

7 Gillman MW, Pinto BM, Tennstedt S, Glanz K, Marcus B, Friedman RH. Relationships of physical activity with dietary behaviors among adults. Preventive Medicine 2001; 32: 295-301.

8 Tormo MJ, Navarro C, Chirlaque MD, Barber X, Argilaga S, Agudo A, et al. Physical sports activity during leisure time and dietary intake of foods and nutrients in a large Spanish cohort. International Journal of Sport Nutrition and Exercise Metabolism 2003; 13: 47-64.

9 Kriska AM, Caspersen CJ. Introduction to a collection of physical activity questionnaires. In: Pereira MA, FitzerGerald SJ, Gregg EW, Joswiak ML, Ryan WJ, Suminski RR, et al., eds. A Collection of Physical Activity Questionnaires for Healthrelated Research [special issue]. Medicine and Science in Sports and Exercise 1997; 29(Suppl. 6): S5-9.

10 Wagner A, Simon C, Evans A, Ferrieres J, Montaye M, Ducimetiere $\mathrm{P}$, et al. Physical activity and coronary event incidence in Northern Ireland and France: the Prospective Epidemiological Study of Myocardial Infarction (PRIME). Circulation 2002; 105: 2247-52.

11 Barengo NC, Hu G, Lakka TA, Pekkarinen H, Nissinen A, Tuomilehto J. Low physical activity as a predictor for total and cardiovascular disease mortality in middle-aged men and women in Finland. European Heart Journal 2004; 25: 2204-11.

12 Hickey N, Mulcahy R, Bourke GJ, Graham I, Wilson-Davis K. Study of coronary risk factors related to physical activity in 15171 men. British Medical Journal 1975; 3: 507-9.

13 Holme I, Helgeland A, Hjermann I, Leren P, Lund-Larsen PG. Physical activity at work and at leisure in relation to coronary risk factors and social class. A 4-year mortality follow-up. The Oslo study. Acta Medica Scandinavica 1981; 209: $277-83$.

14 Seidell JC, Cigolini M, Deslypere JP, Charzewska J, Ellsinger $\mathrm{BM}$, Cruz A. Body fat distribution in relation to physical activity and smoking habits in 38-year-old European men. The European Fat Distribution Study. American Journal of Epidemiology 1991; 133: 257-65.

15 Duncan BB, Chambless LE, Schmidt MI, Szklo M, Folsom AR, Carpenter MA, et al. Correlates of body fat distribution. Variation across categories of race, sex, and body mass in the atherosclerosis risk in communities study. The Atherosclerosis Risk in Communities (ARIC) Study Investigators. Annals of Epidemiology 1995; 5: 192-200.

16 Greendale GA, Bodin-Dunn L, Ingles S, Haile R, BarrettConnor E. Leisure, home, and occupational physical activity and cardiovascular risk factors in postmenopausal women. The Postmenopausal Estrogens/Progestins Intervention (PEPI) Study. Archives of Internal Medicine 1996; 156: 418-24.

17 Pols MA, Peeters PH, Twisk JW, Kemper HC, Grobbee DE. Physical activity and cardiovascular disease risk profile in women. American Journal of Epidemiology 1997; 146: $322-8$.

18 Gustat J, Srinivasan SR, Elkasabany A, Berenson GS. Relation of self-rated measures of physical activity to multiple risk factors of insulin resistance syndrome in young adults: the Bogalusa Heart Study. Journal of Clinical Epidemiology 2002; 55: 997-1006.

19 Gutierrez-Fisac JL, Guallar-Castillon P, Diez-Ganan L, Lopez Garcia E, Banegas Banegas JR, Rodriguez Artalejo F.
Work-related physical activity is not associated with body mass index and obesity. Obesity Research 2002; 10: 270-6.

20 Thomas F, Rudnichi A, Bacri AM, Bean K, Guize L, Benetos A. Cardiovascular mortality in hypertensive men according to presence of associated risk factors. Hypertension 2001; 37: 1256-61.

21 Baecke JA, Burema J, Frijters JE. A short questionnaire for the measurement of habitual physical activity in epidemiological studies. American Journal of Clinical Nutrition 1982; 36 : 936-42.

22 Pereira MA, FitzerGerald SJ, Gregg EW, Joswiak ML, Ryan WJ, Suminski RR, et al., eds. A Collection of Physical Activity Questionnaires for Health-related Research [special issue]. Medicine and Science in Sports and Exercise 1997; 29(Suppl. 6): $\mathrm{S} 1-205$

23 Philippaerts RM, Westerterp KR, Lefevre J. Doubly labelled water validation of three physical activity questionnaires. International Journal of Sports Medicine 1999; 20: 284-9.

24 Bigard AX, Duforez F, Portero P, Guezennec CY. Assessment of physical activity by questionnaire: validity of the Baecke questionnaire. Science \& Sports 1992; 7: 215-21 (in French).

25 Jacobs DR Jr, Ainsworth BE, Hartman TJ, Leon AS. A simultaneous evaluation of 10 commonly used physical activity questionnaires. Medicine and Science in Sports and Exercise 1993; 25: 81-91.

26 Richardson MT, Ainsworth BE, Wu HC, Jacobs DR Jr, Leon AS. Ability of the Atherosclerosis Risk in Communities (ARIC)/Baecke Questionnaire to assess leisure-time physical activity. International Journal of Epidemiology 1995; 24: 685-93.

27 Lasfargues G, Vol S, Le Clesiau H, Bedouet M, Hagel L, Constans T, et al. Validity of a short self-administered dietary questionnaire compared with a dietetic interview. Presse Medicale 1990; 19: 953-7.

28 Lecomte P, Vol S, Caces E, Lasfargues G, Combe H, Laurent S, et al. Impaired fasting glycaemia and undiagnosed diabetes: prevalence, cardiovascular and behavioural risk factors. Diabetes \& Metabolism 2002; 28: 311-20.

29 Nunez C, Gallagher D, Visser M, Pi-Sunyer FX, Wang Z, Heymsfield SB. Bioimpedance analysis: evaluation of leg-toleg system based on pressure contact footpad electrodes. Medicine and Science in Sports and Exercise 1997; 29: 524-31.

30 Salonen JT, Slater JS, Tuomilehto J, Rauramaa R. Leisure time and occupational physical activity: risk of death from ischemic heart disease. American Journal of Epidemiology 1988; 127: 87-94.

31 Elwood PC, Yarnell JW, Pickering J, Fehily AM, O'Brien JR. Exercise, fibrinogen, and other risk factors for ischaemic heart disease. Caerphilly Prospective Heart Disease Study. British Heart Journal 1993; 69: 183-7.

32 Lahti-Koski M, Pietinen P, Heliovaara M, Vartiainen E. Associations of body mass index and obesity with physical activity, food choices, alcohol intake, and smoking in the 1982-1997 FINRISK Studies. American Journal of Clinical Nutrition 2002; 75: 809-17.

33 Bertrais S, Beyeme-Ondoua JP, Czernichow S, Galan P, Hercberg S, Oppert JM. Sedentary behaviors, physical activity, and metabolic syndrome in middle-aged French subjects. Obesity Research 2005; 13: 936-44.

34 Bertrais S, Preziosi P, Mennen L, Galan P, Hercberg S, Oppert JM. Sociodemographic and geographic correlates of meeting current recommendations for physical activity in middleaged French adults: the Supplementation en Vitamines et Mineraux Antioxydants (SUVIMAX) Study. American Journal of Public Health 2004; 94: 1560-6.

35 Jousilahti P, Vartiainen E, Tuomilehto J, Puska P. Sex, age, cardiovascular risk factors, and coronary heart disease: a prospective follow-up study of 14786 middle-aged men and women in Finland. Circulation 1999; 99: 1165-72. 
36 Ness AR, Powles JW. Fruit and vegetables, and cardiovascular disease: a review. International Journal of Epidemiology 1997; 26: 1-13.

37 Hu FB, Willett WC. Optimal diets for prevention of coronary heart disease. Journal of the American Medical Association 2002; 288: 2569-78.

38 Wagner A, Simon C, Evans A, Ducimetiere P, Bongard V, Montaye M, et al. PRIME Study Group. Physical activity patterns in 50-59 year men in France and Northern Ireland. Associations with socio-economic status and health behaviour. European Journal of Epidemiology 2003; 18: 321-9.

39 Liu S, Sesso HD, Manson JE, Willett WC, Buring JE. Is intake of breakfast cereals related to total and cause-specific mortality in men? American Journal of Clinical Nutrition 2003; 77: 594-9.

40 Perrin AE, Dallongeville J, Ducimetiere P, Ruidavets JB, Schlienger JL, Arveiler $\mathrm{D}$, et al. Interactions between traditional regional determinants and socio-economic status on dietary patterns in a sample of French men. British Journal of Nutrition 2005; 93: 109-14.

41 Baecke JA, Burema J, Frijters JE, Hautvast JG, van der WielWetzels WA. Obesity in young Dutch adults: II, daily life-style and body mass index. International Journal of Obesity 1983; 7: $13-24$.

42 Kaplan GA, Keil JE. Socioeconomic factors and cardiovascular disease: a review of the literature. Circulation 1993; $\mathbf{8 8}$ $1973-98$
43 Marmot MG, Bosma H, Hemingway H, Brunner E, Stansfeld S. Contribution of job control and other risk factors to social variations in coronary heart disease incidence. Lancet 1997; 350: $235-9$.

44 Rothenbacher D, Hoffmeister A, Brenner H, Koenig W. Physical activity, coronary heart disease, and inflammatory response. Archives of Internal Medicine 2003; 163: 1200-5.

45 Tremblay A, Doucet E. Influence of intense physical activity on energy balance and body fatness. Proceedings of the Nutrition Society 1999; 58: 99-105.

46 Bjorntorp P. Do stress reactions cause abdominal obesity and comorbidities? Obesity Reviews 2001; 2: 73-86.

47 Fransson E, De Faire U, Ahlbom A, Reuterwall C, Hallqvist J, Alfredsson L. The risk of acute myocardial infarction: interactions of types of physical activity. Epidemiology 2004; 15: $573-82$.

48 Wagner A, Simon C, Ducimetiere P, Montaye M, Bongard V, Yarnell $\mathrm{J}$, et al. Leisure-time physical activity and regular walking or cycling to work are associated with adiposity and 5 y weight gain in middle-aged men: the PRIME Study. International Journal of Obesity and Related Metabolic Disorders 2001; 25: 940-8.

49 Hu G, Qiao Q, Silventoinen K, Eriksson JG, Jousilahti P, Lindstrom J, et al. Occupational, commuting, and leisuretime physical activity in relation to risk for type 2 diabetes in middle-aged Finnish men and women. Diabetologia 2003; 46: 322-9. 